\title{
SABERES SOBRE O TRABALHO: EXPERIÊNCIA E HISTÓRIA NOS CANAVIAIS
}

\author{
CONOCIMIENTO SOBRE EL TRABAJO: EXPERIENCIA E HISTORIA EN \\ PLANTACIONES DE CAÑA DE AZÚCAR \\ KNOWLEDGE ABOUT THE WORK: EXPERIENCE AND HISTORY IN THE \\ SUGARCANE FIELDS \\ Marcela Sobreira Silva \\ Pontifícia Universidade Católica de Minas Gerais e Instituto DH: Promoção, Pesquisa e Intervenção em \\ Direitos Humanos e Cidadania, Belo Horizonte/MG, Brasil
}

Vanessa Andrade de Barros

Universidade Federal de Minas Gerais, Belo Horizonte/MG, Brasil

\begin{abstract}
RESUMO
A agroindústria da cana no Brasil tem ampliado suas dimensões e seu domínio sobre seu território. Politicamente, tal aumento respalda-se na história que associa a produção da cana-de-açúcar ao desenvolvimento econômico e ao progresso nacional (Godoy, 2004). No presente artigo, interrogamos essa versão oficial a partir da história concreta, fruto da vida dos trabalhadores rurais e das experiências vividas nos canaviais. Trata-se de pesquisa desenvolvida durante o Mestrado em Psicologia da UFMG, que utilizou como instrumento metodológico o recolhimento de história de vida tal como proposto pela sociologia clínica, em diálogo com as abordagens teórico-metodológicas da psicossociologia do trabalho e ergologia. Mediante a narrativa de um trabalhador na lavoura de cana-de-açúcar, divisamos seus impactos no cotidiano dos sujeitos e na comunidade, revelando uma experiência que se constrói por meio do trabalho rural e traz para o centro dos acontecimentos as vidas e os dramas humanos omitidos na história oficial.
\end{abstract}

Palavras-chave: agroindústria canavieira; trabalho rural; história de vida; saber; experiência.

\section{RESUMEN}

La industria de la caña de azúcar ha ampliado sus dimensiones y dominio en Brasil. Este aumento se basa en la historia que relaciona la producción de caña de azúcar para el desarrollo económico y el progreso nacional (Godoy, 2004). En este artículo, cuestionamos esta versión oficial desde la historia concreta e experiencia de los trabajadores rurales. Esta es una investigación desarrollada durante el Máster en Psicología de la UFMG, que utiliza como herramienta metodológica la historia de vida en la forma propuesta por la sociología clínica en el diálogo con los enfoques teóricos y metodológicos de la Psicosociología del trabajo y ergología. A través de la narración de un trabajador, divisamos los impactos de la industria de la caña de azúcar en la vida cotidiana, revelando una experiencia que se construye a través del trabajo rural y trae la vida y los dramas humanos a un lugar central.

Palabras clave: agroindustria de caña de azúcar; trabajo rural; historia de vida; saber; experiencia.

\begin{abstract}
The sugarcane industry has expanded its dimensions and its dominance in Brazil. Politically, this increase backs on a history that connects the production of cane sugar to economic development and national progress (Godoy, 2004). This paper questions this official version from the story and experiences of rural the workers. The research was developed during the Master in Psychology in UFMG. As methodological tool was used the Life History as proposed by clinical sociology in dialogue with the theoretical and methodological approaches of the socialpsychology of work and ergology. The narrative of a worker of sugarcane industry could reveal the impacts of sugarcane industry daily life of individuals, community and all the experiences omitted in the official history.
\end{abstract}

Keywords: sugarcane industry; rural work; history of life; knowledge; experience. 


\section{Trabalho e história: caminhos da cana}

O século avança e, com ele, uma promessa se anuncia aos brasileiros: o crescimento econômico que nos garantirá, finalmente, uma posição entre os países mais ricos do mundo. Tal promessa é estampada pelas imagens de canaviais espalhados pelo Brasil, que aliam o enriquecimento à possibilidade de uma fonte de energia limpa e renovável.

Iniciativas privadas e governamentais têm articulado forças para o aumento da produção da canade-açúcar e, só no Estado de Minas Gerais, estima-se que, de 2005 a 2014, sejam investidos R \$ 8,5 bilhões em 40 projetos de expansão ou implantação de usinas que farão com que o Estado mais que triplique sua capacidade produtiva (Secretaria de Estado de Desenvolvimento Econômico, 2009).

O respaldo necessário aos novos projetos de investimento no agronegócio é encontrado na história que, elaborada pelo governo a partir do surgimento da grande indústria nos anos 1930, confere à produção da cana-de-açúcar o status de promotora do desenvolvimento econômico e do progresso nacional (Godoy, 2004).

Entretanto, compreendemos que essa história da agroindústria canavieira no Brasil assemelha-se ao que Benjamin (1994) denomina historicismo - a história que se pretende à universalidade e à verdade inquestionável. O historicismo, unívoco por natureza, formula uma sequência de eventos e os apresenta ao leitor como realidade total. Seu procedimento "é aditivo ... utiliza a massa dos fatos, para com eles preencher o tempo homogêneo e vazio" (Benjamin, 1994, p. 231), porque sem sujeito concreto e sem experiência; tempo reduzido a fatos adicionados que atribuem à história a lógica linear do progresso e do processo evolutivo da técnica. Tempo articulado mecanicamente, acontecimentos encadeados que, na história da produção da cana-de-açúcar veiculada oficialmente pelo governo, apresentam-se como acordos políticos e significam o desenvolvimento econômico.

Nessa história, apenas os eventos protagonizados pelo poder são enfatizados, ocultando a vida dos trabalhadores ou referindose a eles a partir de uma perspectiva externa e não por eles mesmos, por suas vidas, suas trajetórias, o que nos remete a Lejeune (2008), quando afirma que "o vivido das classes dominadas não está em suas próprias mãos", pois "seu vivido é estudado de cima, de um ponto de vista econômico e político" (p. 133).
Buscando uma contraposição a essa perspectiva oficial, encontramos em Schwartz a afirmação de que o fazer histórico do ser social é o trabalho, o que nos oferece a oportunidade de o elegermos como o vetor por meio do qual buscaremos compreender a história do setor sucraleiro, ou seja, a partir da experiência de quem nele trabalha. Para este autor, o trabalho é "sempre, mais ou menos, um momento de história" (2003, p. 22); é atravessado pela história e a faz, na medida em que inaugura uma dupla criação: a do ser humano e do meio social, carregando em si, uma trajetória inacabada, sempre aberta ao novo. Ignorar essa premissa, como o faz a perspectiva oficial, "é desconhecer o trabalho, é mutilar a atividade dos homens e das mulheres que, enquanto 'fabricantes' de história, re-questionam os saberes, reproduzindo em permanência novas tarefas para o conhecimento" (Schwartz, 2003, p. 23). Como lugar prioritário do saber e da experiência, o trabalho produz história e constrói o social reescrevendo e reinventando, incessantemente, a vida humana - suas singularidades e contradições.

Nesse sentido, através da análise ergológica da atividade de produção da cana-de-açúcar, apreendida por meio da história de vida de um trabalhador, abordaremos, neste artigo, uma peculiar dimensão histórica da agroindústria canavieira: aquela que se vive e se faz por meio do trabalho rural, pois, como afirma Ferrarotti (1990) as histórias de vida compreendem uma concepção mais rica e mais vasta da historicidade, uma historicidade não historicista. Para tal, o percurso metodológico, como nos ensina Vincent de Gaulejac (Gaulejac, Marquez, \& Ruiz, 2005), seguiu apenas uma orientação: manter a abertura à dinâmica da realidade, delineando o conhecimento a partir do que ela nos apresenta. Nas palavras de Lévy (Gaulejac \& Lévy, 2000, p. 3),

realçando a maneira pela qual a história social é subjetivamente vivida, as histórias de vida constituem uma via de acesso insubstituível aos processos que sustentam a sociedade em suas diferentes dimensões psicológicas, culturais, econômicas, sociais, tanto em seu movimento histórico quanto em sua atualidade .

Assim é que neste estudo, a realidade investigada é apreendida pelas histórias de vida e de trabalho de Dimas, um trabalhador da produção da cana-deaçúcar, que viveu nessa labuta de 1976 a meados de 1990, na cidade de Lagoa da Prata, Minas Gerais. De origem rural, Dimas viveu sua infância e juventude em Santa Vitória, no triângulo mineiro, ocupando-se do trabalho na roça, junto aos 8 irmãos, e dos longos caminhos percorridos entre a roça e a cidade em busca de estudos e participação na comunidade religiosa. 
Apesar das dificuldades, ingressou na escola agrícola de Igarapava-MG, onde se formou técnico em 1975. A ida para Lagoa da Prata ocorreu no ano seguinte, onde Dimas tinha familiares e a oportunidade de emprego na usina de açúcar.

Seus relatos foram gravados no período de 1 ano, em encontros realizados em sua própria casa. Diante do convite "Conte-me sua história", Dimas contou sua vida livremente, da maneira como the convinha (Gaulejac, Marquez, \& Ruiz, 2005). Além de sua infância e juventude no triângulo mineiro, de seus vínculos com o mundo rural e sua religiosidade, compartilhou também suas histórias de trabalho e de luta pela vida e pelos direitos dos trabalhadores rurais, o que nos ajudou a construir a compreensão do sujeito em sua relação com a atividade: como gerir a distância entre as prescrições da tarefa e as exigências do mundo real; como equacionar a relação entre o mundo de valores, as normas e as renormalizações necessárias e como fazer as escolhas e as micro regulações cotidianas. É desse universo do trabalho, singularizado em uma experiência, que trataremos a seguir.

\section{Os agrotóxicos na cana-de-açúcar: um olhar ergológico}

Dentre os problemas mais graves na produção da cana-de-açúcar encontramos o uso de agrotóxico, e aqui a trajetória de vida de Dimas é particularmente importante para compreendermos os efeitos dessas substâncias sobre a saúde do trabalhador.

Amplamente utilizados em praticamente toda produção agrícola, os agrotóxicos agem no processo produtivo eliminando fatores indesejáveis como fungos, insetos e até mesmo plantas que possam vir a comprometer a produção. Seu uso é, atualmente, considerado fundamental ao empreendimento agrícola, tornando a produção mais eficaz e menos susceptível à perda de produtos e de investimento financeiro. $\mathrm{O}$ maior uso dessas substâncias é na monocultura de grandes extensões (Domingues et al., 2004), onde identificamos a produção da cana-de-açúcar.

Os trabalhadores responsáveis pela aplicação do agrotóxico estão a ele expostos e os riscos à saúde dependem de fatores como: toxicidade do produto em humanos, condições e níveis de exposição. Os efeitos dessa exposição são assim caracterizados: agudo, em que a reação é imediata ao contato com a substância; subagudo, cuja sintomatologia é vaga e subjetiva e o aparecimento é lento; crônico, que se determina por uma exposição prolongada, com danos como paralisias e neoplasias (Domingues et al., 2004).
Dimas tinha como função a manipulação e aplicação de adubos e agrotóxicos utilizados no canavial.

minha trajetória lá de serviço foi mais ou menos com essas duas coisas básicas: o adubo e depois os defensivos, que são veneno. $E$ aí, dentro desses defensivos, eu tive muita dificuldade. Eu acabei adquirindo intoxicação e com essas intoxicação, eu tive um prejuizo de vida danado. Porque a intoxicação, ela causa muita revolução no organismo da gente.

Os efeitos dessa atividade em sua saúde foram devastadores; foi acometido por problemas como: baixa imunidade, queda de plaquetas no sangue, falta de apetite, sonolência, dores de cabeça e musculares, dermatose, entre outros. O adoecimento progressivo conduziu a um longo período de internação no Hospital das Clínicas de Belo Horizonte e o consequente encaminhamento para a aposentadoria, já que a única maneira de controlar os agravos provocados pela intoxicação era o afastamento imediato dos produtos nocivos.

De acordo com a sintomatologia apresentada por Dimas, percebemos que o contato com produtos tóxicos resultou em uma sequela do tipo subaguda e, se a sua exposição ao produto não tivesse sido interrompida, o quadro clínico poderia evoluir para uma intoxicação crônica, com consequências irreversíveis.

Outro fator de risco importante inerente ao manuseio dos agrotóxicos é a instalação do adoecimento mental. Embora grande parte dos estudos sobre a relação entre o uso do defensivo agrícola e os problemas psíquicos seja inconclusiva e mesmo que o estabelecimento do nexo causal entre situação de trabalho e doença mental seja complexo, as evidências e as constantes demandas por internações em instituições de saúde mental do trabalhador têm alertado médicos e psicólogos. Nesse sentido, Araújo, Pinheiro e Greggio (2011) evidenciam que as intoxicações por agrotóxicos

podem desencadear episódios semelhantes aos aspectos delirantes (ou outros) de um quadro esquizofrênico, mesmo quando nenhum traço clínico de psicose conste nos prontuários médicos desses sujeitos ou em seus próprios relatos, por ocasião dos atendimentos médico e psicológico. Com efeito, quando os produtos organofosforados atingem o sistema neuropsicológico, diversos sintomas aparecem, evidenciando que a estrutura psíquica do indivíduo foi gravemente afetada. Aqui aparecem condutas como tentativas de suicídio, abandono familiar, abandono do trabalho, além de outras, que refletem o estado de desalento ou de "sem-saída", face a uma situação de vulnerabilidade estrutural, no plano psicossocial, geradora de intenso sofrimento. (p. 50) 
Os autores ponderam ainda que, além do contato com agrotóxicos, é preciso atentar para os demais fatores que envolvem o trabalho e a vida do sujeito rural, tais como: a precária condição socioeconômica, o excesso de atividades, os riscos de adoecimento e acidentes que lhe são inerentes e a impossibilidade de controlar as forças da natureza. Ou seja, o diagnóstico de adoecimento mental em um trabalhador do campo deve considerar os diferentes aspectos presentes no seu cotidiano, em que se configura um quadro de vulnerabilidade psicossocial marcado por problemas nas condições e na organização do trabalho ${ }^{1}$ que, por sua vez, potencializam a exposição do trabalhador, prejudicando ainda mais sua saúde. O relato de Dimas evidencia sua experiência a esse respeito:

o tempo, quando tá de mais chuva, os mato cresce com uma velocidade espantosa, então pra atender uma demanda de uma usina de, na época tinha uns 18 mil hectares... assim, se fosse contar tudo, tudo, não passava nos 18 mil, mas uma boa parte precisava passar e tinha onde era capinado com ferramenta manual, enxada, outros lugar arrancava moita com enxadão, mas tinha outras parte, mais ou menos $1 / 3$ desse terreno era passado o veneno, então tinha que correr bastante mesmo. Agora, esses, às vezes até mais de $1 / 3$, porque $2 / 3$ era mais ou menos de cana que se cortava durante o ano, agora quando era os tratos culturais, seja no plantio também, ou pra cana que foi plantada ou até no plantio, tinha que jogar também os produtos, então podia ser $1 / 3$, mas às vezes até mais que $1 / 3$, porque a gente acompanhava também esses setores de plantio, jogando os veneno, ou pra não nascer o mato, ou pra matar o mato que nascesse dentro da cana plantada. Então era muita terra que a gente precisava acudir e acompanhar pra não dar mato. Então no que a gente ta falando de andar depressa, mas os cuidados que a gente tinha que ter, esses cuidados preliminares, eu sempre tive, embora os equipamento, em princípio a empresa não fornecia também não, aí quando a gente começou a ter consciência, começou a perceber que o trem era perigoso, ai eu mesmo, da minha parte, comecei a comprar alguns equipamentos, uma mascarazinha, algumas luva e fazia esse cuidado de tá usando esses EPI'. Mas a dificuldade foi muito grande nesse tempo de ter que trabalhar com rapidez num produto perigoso desse tanto. Eu trabalhava domingo, dia santo, feriado, enrolava tudo! Às vezes, num domingo até não ia, mas era difícil não ir, normalmente ia até meio-dia, duas horas, pelo menos isso.

A exigência de um intenso ritmo produtivo, com o manuseio de um produto nocivo à saúde e ainda sem a devida proteção, configura um meio e uma série de normas no trabalho que não correspondem àqueles necessários à vida humana, aos valores humanos, como discutido por Canguilhem (2001). Prova disso é o depoimento de Dimas, que nos alerta para aspectos como o ritmo e a intensidade de sua atividade, exercida de forma a expor ao risco sua saúde e segurança. As normas impostas para a produção envolvem rapidez e exigência de resultados definidos pela empresa e pelo ritmo e velocidade das máquinas.

Nesse sentido, as considerações de Canguilhem (2001) são claras e diretas: não existe a possibilidade de os trabalhadores tomarem

como autenticamente normais senão as condições de trabalho que eles mesmos teriam instituído em referência a valores próprios e não emprestados, e que o meio de trabalho que eles tomariam como normal seria aquele que eles teriam feito eles mesmos, a eles mesmos, para eles mesmos. Todo homem quer ser sujeito de suas normas. A ilusão capitalista está em acreditar que as normas capitalistas são definitivas e universais, sem pensar que a normatividade não pode ser um privilégio. (p. 120)

Desse modo, não só o processo produtivo da canade-açúcar, mas toda a produção de bens e materiais para o uso do homem seria outra se as normas operadas nas etapas da atividade fossem construídas pelo próprio trabalhador. Ainda como nos ensina Canguilhem (2001), o erro de Taylor e de toda a produção regida pelo modo capitalista reside na tentativa de definir as condições e a organização do trabalho, sem ponderar a incapacidade de se prever inteiramente o trabalho humano, desconsiderando, ainda, a possibilidade de renormatizações protagonizadas pelos trabalhadores.

Ou seja, a rigidez de um modo de produção conduzido pelo ritmo das máquinas e da acumulação e ditado hierarquicamente pelos gestores da empresa pretende ao rigor e ao cumprimento de tarefas que eliminam a subjetividade. Nesse contexto, o trabalhador é mero objeto de produção e não um sujeito capaz de intervir e criar as próprias normas; mas não é o que ocorre no trabalho real, que, transbordando as prescrições, exige renormatizações. Como enfatiza Schwartz (2007), o meio é infiel, porque irrepetível e imprevisível; e é imerso nessas infidelidades que o ser humano faz "usos de si", cria, transforma e intervém com suas próprias capacidades, utilizando-se dos recursos e escolhas que lhe são particulares.

Nesse sentido, compreendemos a atitude de Dimas, que, consciente dos riscos de sua atividade à saúde, providenciou o seu equipamento de proteção, estabelecendo, assim, as próprias normas e agindo de acordo com os seus valores. Entretanto, não escapou da pressão, das exigências da produção:

Eu até fiz umas extravagância, que não devia, já misturei trem com a mão também, mas sempre esticava o braço mais que pudesse, virava o rosto 
pro outro lado, e ai então, fazia as mistura, colocava os produto dentro d'água e ficava contra o vento também toda situação que pudesse, pra não ter tanta incidência em cima da gente. Mas mesmo assim, teve algumas problemáticas quanto a essas situações. Tinha um outro jeito de aplicar também, até na época, ele chamava de canhão, é uma bomba de 400 litros, acho que 400 mesmo... 200! 200 litros. E ela tinha uma boca grande, com um diâmetro duns $30 \mathrm{~cm}, 20$, 30 e aquela boca grande dirigia o jato pra jogar nos mato, e ai era mato grande, e esse trem jogava longe, uns 40 metros, 30, por ai! E ai tinha de o operador sentar no paralama do trator e ia dirigindo aquele jato, jogando pra trás, jogando aquilo pra trás nos mato alto. E esse também era muito dificil porque com esse jato forte, com essa boca larga desse jeito, muitas vezes o vento virava e jogava os produto em cima do operador e do tratorista e tudo. E mesmo que tivesse os chamado EPI, a proteção não é aquela que precisa pra esse tanto de produto. Eu também já dirigi esse jato algumas vezes, não foi poucas vezes não, $e$ já tomei saraivada de produto, por causa do vento virar pra cima da gente; então, tudo isso acabou acarretando pra minha saúde algumas debilidades que a gente carrega até hoje.

Na situação vivida por ele, as normas e os valores imbricados no processo do trabalho não se abriram em debate, como propõe Schwartz (2007). As exigências da empresa não foram dialogadas com as necessidades dos trabalhadores (pelo menos não naquele momento). Desse modo, Dimas agiu, em sua atividade, da maneira que considerou o melhor modo possível a fim de exercer o papel que lhe era designado e responder às metas da produção ao mesmo tempo que tentava renormatizar, proteger-se dos perigos inerentes à sua função.

A normatização do processo produtivo da canade-açúcar não prioriza a saúde e a segurança do trabalhador rural, além de impossibilitar a realização de uma atividade bem feita, orientada pela vontade e pelas determinações autônomas do trabalhador.

Diante da necessidade de renormatização é que Dimas age nos limites de sua possibilidade e escolhe proteger-se com os equipamentos necessários e evitar sua exposição ao produto. Contudo, as medidas de proteção são insuficientes para que se possa evitar o adoecimento e, para realizar a tarefa, permanece, em algumas situações, exposto aos perigos da sua atividade.

As pontuações de Schwartz (2007) a respeito das escolhas no trabalho ajudam-nos a refletir sobre esta condição vivida por Dimas:

É verdade que, no trabalho, há sempre uma espécie de destino de viver. Não há outro jeito, sempre é necessário fazer escolhas. Se fazemos escolhas, por um lado elas são feitas em função de valores - mas, por outro, essas escolhas são um risco, já que é preciso suprir os "vazios de normas", as deficiências de orientações, de conselhos, de experiências adquiridas, registradas nas regras ou nos procedimentos. (p. 193)

Não precisamos discorrer novamente acerca de como os riscos assumidos por Dimas lhe custaram a saúde; ressaltamos somente que as propostas elaboradas por Schwartz (2007) para a solução deste problema supõem uma gestão empresarial do trabalho aberta às normas e valores criados pelos trabalhadores, promovendo, assim, os debates e as constantes e necessárias renormatizações.

\section{Vida e meio ambiente: os desgastes da cana}

A possibilidade de um redesenho do trabalho rural na cana-de-açúcar não é vislumbrada; valemo-nos do trabalho de profissionais e pesquisadores engajados na proteção do trabalhador rural e na garantia dos direitos nos canaviais para pontuar que a exigência de resultados prevalece como uma norma irrevogável cumprida sob a pena da violação dos direitos e do abuso no emprego dos agrotóxicos ${ }^{3}$.

A respeito do uso de produtos agroquímicos, o jornal O Estado de São Paulo publicou, no dia 09 de junho de 2010, a informação de que o Brasil é o principal destino de agrotóxicos proscritos em diferentes países ("Campeão", 2010). O aumento dessa importação, no período de um ano (2008 a 2009), computou o dado alarmante de $29 \%$, com a previsão de crescimento gradual para os anos subsequentes.

Obviamente, não é todo o agrotóxico importado pelo país que se destina à produção da cana-de-açúcar; porém, cientes do plano de expansão e do investimento por parte do governo brasileiro nesse setor produtivo, constatamos, imediatamente, que parte da distribuição de tais produtos contempla a indústria sucroalcooleira.

Nesse contexto, lembramos que o uso dos agrotóxicos não afeta apenas o sujeito que lida diretamente com os referidos produtos. O meio ambiente, assim como o trabalhador, também é prejudicado, na medida em que a toxicidade dos resíduos químicos atinge a terra, o ar e os lençóis freáticos.

Estudos realizados em diferentes áreas de cultivo da cana-de-açúcar revelam o alto índice de contaminação dos recursos hídricos presentes nas regiões adjacentes às plantações. Essa contaminação é atribuída à heterogeneidade de tipos e classes de 
agrotóxicos utilizados em quantidade exagerada. As consequências de tal uso são alarmantes, pois a persistência desses produtos no ambiente é alta e o prejuízo das águas repercute na vida dos animais e dos seres humanos que delas dependem. (Corbi et al., 2006; De Armas et al., 2005)

Os defensores dos Direitos Humanos no Brasil atribuem o problema da degradação ambiental ao processo de modernização da agricultura inerente à implantação do modelo de desenvolvimento adotado pelo governo. Tal modelo é caracterizado pela monocultura de exportação e sustentado pela concentração de renda e de terras.

Segundo Pádua (2003), a sociedade brasileira sofreu um processo de transformação significativo a partir da década 1940, devido ao intenso êxodo rural impulsionado por uma crise que impossibilitou a sobrevivência de milhares de famílias nesse meio. $\mathrm{O}$ autor afirma que, nesse período, grande parcela da população vivenciou um processo de "desruralização", sem que se conseguisse transformar a realidade agrária brasileira, historicamente dominada pela concentração de poder e de riqueza. Desse modo,

no complexo contexto histórico da segunda metade do século XX, ... o crescimento da urbanização e da industrialização se superpôs a uma estrutura agrária essencialmente concentrada e desigual. Foi sobre esse quadro que também se implantou uma rápida dinâmica de transformação da economia rural, expressa no desenvolvimento de complexos agroindustriais fundados na motomecanização, na irrigação e no uso crescente de insumos químicos. Essa dinâmica de crescimento da grande propriedade capitalista e empresarial gerou uma série de problemas socioambientais para as populações que vivem nos espaços rurais e florestais, especialmente nas fronteiras de expansão do agronegócio. (p. 51)

Evidenciamos que os resultados dos direcionamentos desenvolvimentistas operados por meio do investimento agroindustrial ameaçam o meio ambiente e as fontes naturais essenciais à vida. Especificamente no processo produtivo da canade-açúcar, o uso dos agrotóxicos ocorre em meio à monocultura que provoca a perda da biodiversidade natural e o esgotamento progressivo dos recursos biológicos próprios àquele meio.

Segundo Roseiro e Takayanagui (2004), a prática da monocultura da cana induz ao dano ambiental, "pondo em desequilíbrio toda a fauna e a flora e as condições físico-químicas do solo, na viabilidade de novas culturas" (p. 81). As autoras assinalam, ainda, os riscos que a queima das plantações de cana-de-açúcar conferem ao meio ambiente. Necessária ao corte da cana, a sua combustão libera poluentes que prejudicam a qualidade do ar e trazem danos ao solo, às plantas, à fauna e até mesmo à população, especialmente grupos vulneráveis, como crianças e idosos.

Dessa forma, a monocultura associada à aplicação de agrotóxicos e à prática da queima é uma atividade ecologicamente devastadora, pois, desgastado em sua diversidade biológica, o meio ambiente torna-se incapaz de reagir às agressões provocadas pelo uso de produtos químicos e pelos resíduos da combustão. Por isso, a preocupação com o emprego dos agrotóxicos nos canaviais é sentida por Dimas em todo o seu processo - do manuseio ao descarte.

Outra coisa também que é dificil desse trem, desse veneno, as embalagens, por exemplo, se você ajunta as embalagens pra fazer uma queima, você vai poluir o ambiente, o ar, se você pega as embalagens e deixa ao ar livre, é a mesma coisa, fica atrapalhando o ar, a atmosfera. Se joga num buraco, enterra aquilo, você está atrapalhando o lençol freático. O trem vai, a chuva vai caindo em cima, o trem vai descendo, vai descendo, até encontrar o lençol freático. É o caso de região que joga muito veneno, as águas são poluidas com esse negócio, porque não tem como segurar nas parte alta ou longe das águas, onde tem um córrego, onde tem uma nascente, uma lagoa, um rio, não tem como segurar isso fora, se você joga perto. Se você jogar por perto desses lugares, a chuva que cai leva parte desses produtos pra dentro das águas e se não tem nesses lugar o que eu to falando, córrego, rio, lagoa, noutros lugar tem lençol freático também. Então, você joga sempre, joga todo mês, ou joga tantas vezes por ano, ta sempre jogando, jogando, jogando, aquilo vai descendo na terra, descendo até um determinado tempo vai encontrar o lençol freático e ai vai atrapalhando tudo, vai contaminando.

O raciocínio de Dimas sobre as proporções que o descarte de produtos tóxicos pode alcançar é realmente alarmante. Considerando que a aplicação dos agrotóxicos ocorre em vários estágios de cultivo da cana-de-açúcar, compreendemos que os impactos sobre o ambiente podem atingir uma amplitude maior do que as áreas diretamente ligadas e mais próximas aos canaviais. Isso porque o processo de lixiviação do solo faz com que esses produtos químicos se espalhem, atingindo rios e seres vivos, mesmo que não estejam imediatamente relacionados com essas plantações (Corbi et al., 2006).

Entretanto, a postura do Governo Federal e do Estado desconsidera abertamente os problemas humanos e ambientais que advêm da produção de cana-de-açúcar. Sob a bandeira da proteção ambiental, a política nacional tem investido em programas 
de ampliação da agroindústria canavieira, que é apresentada como uma fonte geradora de energia limpa. Limpa, porque renovável, energia provinda da luz solar convertida pelas plantas e que, ao contrário do petróleo, é inesgotável.

Anunciando o cuidado e a preocupação com o meio ambiente, o Brasil lidera o grupo de países que investem em energia limpa e renovável. A preservação justifica, para os líderes do nosso país, os programas de implantação e expansão dos canaviais. Por isso, os discursos que apresentam esses programas são repletos de conteúdos direcionados à conservação do planeta.

Embora o apelo ambiental seja mais evidente na última década, historicamente a implantação e o estímulo à produção de usinas sucroalcooleiras são justificados pelo governo como uma forma de cuidado com a natureza e preservação dos recursos naturais. Por isso, no encontro dos produtores do açúcar realizado em $1976^{4}$, o pesquisador americano Melvin Calvin foi convidado a expor sua pesquisa sobre as vantagens ambientais da extração de energia da canade-açúcar.

A primeira vantagem exibida pelo pesquisador está relacionada à compreensão de que se trata de uma energia com fonte ilimitada. Conforme explica Calvin, todas as maneiras elaboradas pelo homem para a obtenção de energia são ineficientes, pois vulneráveis ao esgotamento dos recursos naturais capazes de fornecer a energia e manter a vida na Terra.

Assim, o pesquisador caracteriza a energia obtida por meio do petróleo, do gás natural, do carvão e das águas como limitada.

Entretanto, sobra outra alternativa que continua crescer a cada dia, qual seja o sol e essa é a mensagem que trago a vocês hoje. Precisamos usar a energia solar que vem a nós todos os dias ... Agora, como podemos fazer isto? Como podemos usar o sol? Quais são as maneiras de usá-lo? ... As plantas verdes, a cana-deaçúcar e outras sabem como usar essa energia, sem graduá-la, sem transformá-la em energia térmica, aproveitando-a diretamente. A cana-de-açúcar pode fazer isso, e é o meio mais eficiente de energia solar que temos hoje. (Associação Promotora de Estudos da Economia - APEC / Cooperativa Fluminense dos Produtores de Açúcar e Álcool - COPERFLU, 1977, pp. 13, 16)

Dessa maneira, a energia obtida por meio da cana-de-açúcar é comumente referida como renovável, já que capta diretamente a luz solar - uma fonte inesgotável - e a transforma em recurso energético para a humanidade. Colhida e utilizada para as necessidades humanas, replantam-se as mudas e renova-se, assim, o ciclo. Trata-se de energia retirada das plantas e que demanda da natureza apenas o sol e as terras.

Nesse aspecto, Calvin declara: "Isto me trouxe ao Brasil, porque ele tem, não só grande quantidade de sol e de terra, mas também porque produz mais canade-açúcar que qualquer outro país do mundo. Tem sido assim por muitos anos" (APEC / COPERFLU, 1977, p. 17).

A segunda e terceira vantagens ambientais da energia provinda da cana-de-açúcar são apresentadas rapidamente pelo pesquisador americano que afirma que o uso do álcool combustível diminuiria a emissão de monóxido de carbono na atmosfera, tornando o ar menos polú́do e menos prejudicial ao ser humano e ao meio ambiente. Calvin afirma, ainda, que "o índice de produção de oxigênio em um campo de plantação de cana é certamente maior do que em qualquer floresta ... Há uma quantidade, relativamente grande, que é liberada para cada tonelada de carboidrato" (APEC / COPERFLU, 1977, p. 33).

Sendo assim, a exposição desse pesquisador no Encontro Nacional dos Produtores do Açúcar legitimou o discurso da proteção ambiental que já se fazia presente nas iniciativas governamentais voltadas à produção da cana-de-açúcar nos anos 1970. Não é de se surpreender que o conteúdo mostrado por Calvin tenha acabado por inspirar, naquele momento, a declaração do então representante da Associação de Engenheiros e Arquitetos do Norte do Estado do Rio de Janeiro, Aldo Peixoto:

Acreditamos que Deus criou o mundo para nós, sua criação principal, e assim, acho que a vida terá de ser preservada por nós, que devemos conservá-la na superfície da Terra. O senhor tem dedicado sua vida ao estudo dos meios de preservação, por isso agradecemos ao senhor. (APEC / COPERFLU, 1977, p. 31)

Contudo, as afirmações de Calvin realizadas no mencionado encontro não resistem ao mínimo conhecimento sobre as etapas produtivas da cana-deaçúcar e, menos ainda, à experiência concretamente vivida por trabalhadores rurais. Por isso, a vantagem prioritariamente considerada - a plantação de cana como fonte ilimitada de energia - é imediatamente desacreditada, quando compreendemos que o abuso no emprego dos agrotóxicos e na exploração das terras conduz ao empobrecimento do solo e ao desgaste do meio ambiente.

De fato, o álcool combustível emite menos monóxido de carbono do que a gasolina, como declara Calvin. Entretanto, a prática das queimadas nas plantações, anterior ao corte da cana, foi e ainda 
permanece bastante comum nesse processo produtivo, o que torna o argumento da alta produção de oxigênio nos canaviais falacioso ou, pelo menos, amplamente questionável.

Ambos - governos dos anos 1970 e atual referem-se à cana como uma fonte de energia limpa e renovável, denotando, com o uso de tais termos, uma proteção ao ambiente que não corresponde à realidade. Conforme mostramos, a experiência de Dimas revela os impactos desse processo na saúde dos trabalhadores e na diversidade biológica, tão necessária à manutenção da vida.

\section{O trabalho como experiência: fonte de saber e de história}

A trajetória de Dimas nos conduz a uma reflexão sobre o saber e a história gerados pela experiência; sobre o conhecimento que nasce e se apoia no vivido, tecendo uma história composta pela vida humana, suas contradições e sua dinamicidade propiciada pela constante reinvenção.

$\mathrm{O}$ relato de uma vida nos leva à dimensão da experiência que compõe o trabalho como encontro de encontros: encontro do sujeito com sua própria história e de sua atividade, com as normas e com as imprevisibilidades que o meio lhe apresenta. A experiência convoca o sujeito à ação diante da impossibilidade normativa e, por isso, "não deve ser um conceito genérico, precisamos poder individualizála por intermédio de situações e percursos sempre em parte singulares" (Schwartz, 2010, p. 41).

Percurso singular, porque próprio ao sujeito, com os saberes, valores e escolhas que lhe são peculiares e colocados inteiramente em sua atividade. Aqui, deparamo-nos com um ponto que nos é particularmente importante: não só a consciência do sujeito é convocada pela ação, mas seu corpo inteiro é implicado no trabalho, tecendo a experiência. Por isso, segundo Schwartz (2010), o corpo-si ou a pessoa-si é que faz a experiência, contando a história dos "nossos fracassos, nossos sofrimentos, nossos sucessos, nossos engajamentos com uns e outros, atravessados pelas nossas relações com os valores" (p. 43).

Acompanhamos, na trajetória de Dimas, a entrega de seu corpo ao trabalho, deparando-se com problemas, inventando soluções, fazendo escolhas, padecendo sob os agrotóxicos e, enfim, refletindo sobre o processo produtivo da cana-de-açúcar.

Toda a carga de escolha e de conflito presente no trabalho nos faz pensá-lo como experiência, pois não há uma atividade de trabalho que não tenha necessidade de gerir, negociar esse encontro, que há fortemente apelo à pessoa, à sua memória, aos seus debates internos, aos seus hábitos quase domados em seu corpo, a uma multidão de coisas que são os mistérios da experiência. (Schwartz, 2010, p. 44)

Por essa multidão de coisas que compõem a experiência, é que o trabalho gera saberes e delineia histórias. Os saberes da experiência são, por isso, saberes investidos, ou seja, saberes que surgem e ocorrem no seio da atividade, na relação do sujeito com as diversas situações vividas em seu trabalho. E, produzindo o saber, é que se produz, também, a história própria ao trabalho e à complexa atividade sempre em reconstrução (Schwartz, 2003, 2010).

Nossa breve análise do uso dos agrotóxicos na produção da cana-de-açúcar evidencia que a história reproduzida pelo governo difere daquela gerada pela experiência nos canaviais. A história que resume a produção canavieira ao progresso econômico e a acordos políticos não contempla a vida dos trabalhadores e não dimensiona o saber por eles produzido. Pelos trabalhadores, por suas vidas e suas histórias e, principalmente, por seus saberes, percebemos que se trata de uma produção humana e ambientalmente devastadora e, ainda assim, muito rica, complexa e contraditória, justamente por ser experiência vivida por sujeitos.

Tal constatação nos coloca algumas implicações fundamentais a respeito da produção da cana-de-açúcar: (a) o saber reproduzido na história governamental é estéril e limitado, visto que desvinculado do saber produzido incessantemente pelos trabalhadores; (b) a compreensão da história humana que exclui o universo real do trabalho é igualmente estéril e limitada e (c) a história e o saber também se fazem presentes no interior da produção rural, através da vida e da experiência dos trabalhadores.

As implicações nos revelam um cenário preocupante: há uma história e um saber repercutidos que não contemplam toda a realidade da cana-deaçúcar, mas que fundamentam os novos investimentos nesta produção. Neste ponto, é impossível não se engajar em uma perspectiva científica que dialoga e considera o saber do trabalhador e, com ele, contar outra história, revelar uma nova experiência.

\section{Notas}

1 Em nossa pesquisa de mestrado, demonstramos como a organização do trabalho rural na cana-de-açúcar pode gerar uma relação de opressão que se impõe e determina a vida cotidiana do trabalhador (Silva, 2011). 
2 Equipamento de proteção individual (EPI).

3 A Rede Social de Justiça e Direitos Humanos publicou, em abril de 2008, o documento Direitos Humanos e a Indústria da Cana, que analisa "os desdobramentos do agronegócio e da indústria da cana nos direitos humanos, incluindo direitos civis, sociais e ambientais" (Sydow et al., 2008, p. 3). Este material apresenta dados alarmantes sobre a realidade dos canaviais, marcada pela intensificação do trabalho e da produção, com o uso imponderado dos agrotóxicos.

4 O encontro dos produtores do açúcar e do álcool foi realizado em 1976 e reuniu pesquisadores, representantes do governo e empresários e investidores da área. Tal encontro tinha como objetivo viabilizar a lavoura canavieira no Brasil, discutindo as vantagens de sua produção. Interessante notar como a vida e o trabalho das pessoas diretamente envolvidas na produção sequer foram mencionados pelos participantes do encontro.

\section{Referências}

Araújo, J. N. G., Pinheiro, T. M. M., \& Greggio, M. R. (2011). Notas sobre o adoecimento mental em trabalhadores rurais. In J. C. Zanelli, N. Silva, \& S. R. Tolfo (Orgs.), Processos psicossociais nas organizações e no trabalho (pp. 46-60). São Paulo: Casa do Psicólogo.

Associação Promotora de Estudos da Economia - APEC. Cooperativa Fluminense dos Produtores de Açúcar e Álcool - COPERFLU. (1977). IV Encontro Nacional dos Produtores de Açúcar. Cana-de-açúcar: energia e desenvolvimento para o Brasil. Rio de Janeiro: Autor.

Benjamin, W. (1994). Sobre o conceito de história. In W. Benjamin, Obras escolhidas, volume 1. Magia e técnica, arte e politica: ensaios sobre literatura e história da cultura (pp. 222-232). São Paulo: Editora Brasiliense.

Campeão dos agrotóxicos. (2010, 09 de junho). O Estado de São Paulo, p. A3.

Canguilhem, G. (2001, julho/novembro). Meio e normas do homem no trabalho. Pró-posições, 12(2-3), 109-121.

Corbi, J. J. et al. (2006). Diagnóstico ambiental de metais e organoclorados em córregos adjacentes a áreas de cultivo de cana-de-açúcar (Estado de São Paulo, Brasil). Química Nova, 29(1), 61-65.

De Armas, E. D. et. al. (2005). Uso de agrotóxicos em canade-açúcar na bacia do rio Corumbataí e o risco de poluição hídrica. Química Nova, 28(6), 975-982.

Domingues, M. R. et. al. (2004, janeiro/dezembro). Agrotóxicos: risco à saúde do trabalhador rural. Semina: Ciências Biológicas e da Saúde, 25, 45-54.

Ferrarotti, F. (1990). Histoire et histoires de vie: la méthode biographique dans les sciences sociales. Paris: Méridiens Klincksieck.

Gaulejac, V. \& Lévy, A. (2000). Récits de vie et histoire sociale. Revue Internationale de Psychosociologie, 6(14), 3-6.

Gaulejac, V., Marquez, S. R., \& Ruiz, E. T. (2005). Historia de vida Psicoanálisis y Sociologia Clínica. Mexico: Ediciones UAQ.

Godoy, M. M. (2004). No país das minas de ouro a paisagem vertia engenhos de cana e casas de negócio: um estudo das atividades agroaçucareiras tradicionais mineiras, entre o Setecentos e o Novecentos, e do complexo mercantil da província de Minas Gerais. Tese de Doutorado, Faculdade de Filosofia, Letras e Ciências Humanas, Universidade de São Paulo, São Paulo.

Lejeune, P. (2008). O pacto autobiográfico: de Rosseau à internet. Belo Horizonte: Editora UFMG.

Pádua, J. A. (2003). Desenvolvimento humano e meio ambiente no Brasil. In C. Moser \& D. Rech (Orgs.), Direitos humanos no Brasil: diagnósticos e perspectivas: olhar dos parceiros de Misereor (pp. 45-70). Rio de Janeiro: CERIS/ Mauad.

Roseiro, M. N. V. \& Takayanagui, A. M. M. (2004). Meio ambiente e poluição atmosférica: o caso da cana-de-açúcar. Saúde, 30(1-2), 76-83.

Schwartz, I. (2003, janeiro/junho). Trabalho e saber. Trabalho e Educação - Revista do NETE, 12(1), 21 -34.

Schwartz, I. (2007). Trabalho e Ergologia: conversas sobre a atividade humana. Niterói, RJ: Universidade Federal Fluminense (EdUFF).

Schwartz, I. (2010, janeiro/abril). A experiência é formadora? Educação e Realidade, 35(1), 35-48.

Secretaria de Estado de Desenvolvimento Econômico. (2009). Governo de Minas debate o etanol na Assembleia Legislativa. Belo Horizonte: Autor. Acesso em 20 de julho, 2011, em http://www.desenvolvimento.mg.gov.br/index. php?option $=$ com content \&task $=$ view\&id $=287$

Silva, M. S. (2011). Cotidiano e experiência no trabalho rural da cana-de-açúcar em Lagoa da Prata, Minas Gerais: as trajetórias de vida de Dona Alzira e Dimas. Dissertação de Mestrado, Departamento de Psicologia, Universidade Federal de Minas Gerais, Belo Horizonte.

Sydow, E. et al. (2008). Direitos Humanos e a indústria da cana. São Paulo: Rede Social de Justiça e Direitos Humanos.

Submissão em: 24/02/2012

Aceite em: 25/03/2014

Marcela Sobreira Silva é Psicóloga. Mestre em Psicologia pela Universidade Federal de Minas Gerais (UFMG).

Professora da Pontifícia Universidade Católica de Minas Gerais e pesquisadora do Instituto DH: Promoção, Pesquisa e Intervenção em Direitos Humanos e Cidadania. Endereço: Rua Cristal, 89. Bairro Santa Tereza, Belo Horizonte/ Minas Gerais. Brasil. CEP 31.010110 E-mail: sobreira.marcela@gmail.com

Vanessa Andrade de Barros é Psicóloga. Doutora em Sociologia - Université de Paris VII. Professora Adjunta da Graduação e Pós-graduação do Departamento de Psicologia da Universidade Federal de Minas Gerais (UFMG). Universidade Federal de Minas Gerais. E-mail: vanessa.abarros@gmail.com

\section{Como citar:}

Silva, M. S. \& Barros, V. A. (2014). Saberes sobre o trabalho: experiência e história nos canaviais. Psicologia \& Sociedade, 26(2), 440-448. 